\title{
Antioxidant Activity of Avicennia alba Blume, (1826) Family Avicenniaceae, Leaf Extracts Using DPPH Assay
}

\author{
FELITA C. TORERO \\ fctorero@universityofbohol.edu.ph \\ https://orcid.org/0000-0001-9170-9311
}

\begin{abstract}
The antioxidant activity of Avicennia alba Blume, (1826) leaf extract was determined using 1,1-Diphenyl-2-picrylhydrazyl (DPPH) Free Radical Scavenging Activity Assay. Petroleum ether and $95 \%$ ethanol were used as solvents in two separate macerations. Only the ethanolfree extract (TSB) exhibited antioxidant activity; it showed a color change from purple to light yellow similar to positive control (ascorbic acid solution) and a decrease in absorbance relative to negative control (95\% ethanol). The results of the DPPH free radical scavenging activity assay was subjected to statistical analysis using one way ANOVA then post hoc analysis results of TSB showed no significant difference vs positive control, a percentage antioxidant activity of $68.24 \%$ \pm 12.23 and $76.43 \% \pm 9.22$ respectively. The ethanol-free extract (TSB) underwent phytochemical screening by test tube method where it revealed the presence of saponins, tannins, flavonoids, and glycosides. It was then subjected to column chromatography for partial purification of its chemical compounds; fractions from the eulates
\end{abstract}


were collected and were pooled according to their TLC profile specifically $\mathrm{Rf}$ values. The fractions that showed significant spots under UV light were fractions 1 and 2; and fractions 4 and 5. These two sets of fractions were tested to DPPH free radical scavenging assay. Both fractions showed similar color change as the positive control and a decrease in absorbance relative to the negative control. Fractions $1 \& 2$ showed $69.97 \% \pm 2.439$ percentage antioxidant activity which had no significant difference to the positive control with the highest antioxidant activity of $87.88 \% \pm 3.357$. The $p$-value $(<0.01)$ obtained manifested that there was significant difference between the test solutions with their antioxidant activity. After DPPH assay, the most active fractions 1 \& 2, were subjected to FT-IR and GC-MS. Infrared spectrum showed the presence of aliphatic $\mathrm{C}-\mathrm{H}$ bonds, $\mathrm{C}=\mathrm{O}$ bond, and $-\mathrm{OH}$ bonds while the GC-MS analysis revealed five compounds which were based on the molecular ion showed at $\mathrm{m} / \mathrm{z}=537.4$. The functional groups present in the compounds from FT-IR and GC-MS analyses and the secondary metabolites present in phytochemical screening seemed to be responsible for the antioxidant activity of Avicennia alba leaf extracts.

\section{INTRODUCTION}

Medicinal plants have played an essential role on the health and healing of man since the dawn of human civilization (Saikia and Upadhyaya, 2011). Recently, many plants have been investigated in the search for novel antioxidants. Various and many free radical scavenging antioxidants are found in plants. Antioxidants are vital phytochemicals, vitamins, and other nutrients which protect the body from damages brought about by free-radical induced oxidative stress (Vadlapudi \& Naidu, 2009).

Antioxidant substances block the harmful action of free radicals by scavenging the free radicals and detoxifying the organism (Dehpour, Ebrahimzadeh, Nabavi, \& Nabavi, 2009). In vitro and in vivo studies have shown that antioxidants help prevent the free radical damage that is associated with cancer and heart disease. Antioxidants act as free radical scavengers by preventing and repairing damages caused by reactive oxygen species (ROS), therefore enhancing the immune defense and lowering the risk of cancer and degenerative diseases (Pham-Huy, Hua, \& Pham-Huy, 2008 as cited in Ebrahimzadeh, Nabavi, Nabavia, Bahramian, \& Bekhradnia, 2010). 
Mangroves and mangrove associates are widely used throughout the world. Mangroves have been a source of several bioactive compounds; extracts from mangrove species have proven activity against human, animal and plant pathogens. Secondary metabolites like alkaloids, phenolics, steroids, terpenoids have been characterized from mangroves and are said to have toxicological, pharmacological, and ecological importance (Bandaranayke, 2002).

One of the commonly found species of mangrove in the Philippines is the Avicennia alba Blume. It is a grey mangrove locally known as apiapi (Brown \& Fischer, 1918). It has been used for the treatment of sexual disorders, scabies, rheumatism, paralysis, asthma, snake-bites and ulcer (Kar, Sudhir Kumar, Ghosh, \& Sahu, 2014). Resins of the said species of mangrove have been used in birth control, and treatment of skin diseases and tumors (Nagababu \& Umamaheswara Rao, 2012). Studies have also shown that its leaves contain antidiarrheal and antinociceptive properties (Rahman, Biswas, Bala, Shill, \& Bose, 2011).

The study of Terao and Piskul (1997) as mentioned in the study of Ebrahimzadeh et al. (2010), revealed that the most effective components seemed to be flavonoids and phenolic compounds of many plant raw materials, particularly in herbs, seeds, and fruits. Their metal-chelating capabilities and radical scavenging properties have enabled phenolic compounds to be thought of as effective free radical scavengers hence this will protect the human body from diseases. Phenolic compounds (commonly referred to as "flavonoids" or "polyphenols") are ubiquitous phytochemicals present in plant foods with numerous biological activities including antioxidant properties (Zhang, Seeram, Lee, Feng, \& Heber, 2008).

The World Health Organization (2012) reported that the top leading causes of death included ischemic heart disease, stroke, lower respiratory infections and chronic obstructive lung disease while data from the Department of Health (2013) revealed the top three leading causes of mortality in the Philippines -diseases of the heart, diseases of the vascular system and malignant neoplasms. These conditions, however, can be prevented with the use of antioxidants. Although there are several synthetic antioxidants widely used in food like butylatedhydroxyanisole $(\mathrm{BHA})$, butylatedhydroxytoluene $(\mathrm{BHT})$, propygallate $(\mathrm{PG})$, and tertbutylhydroquinone, these artificial chemicals are not free from sideeffects which include toxicity and DNA damage problems (Choi, Lee, Park, \& Sayegh, 2009; Pourmorad, Hosseinimehr, \& Shahabimajd, 2006; 
Kumar, 2014). This, therefore creates a need to substitute them with naturally occurring antioxidants.

The study aimed to determine the antioxidant activity of the leaf extracts of Avicennia alba Blume (1826). Specifically, the study aimed to:

1. compare the color change of 1,1-Diphenyl-2-Picrylhydrazyl (DPPH) of the extracts

2. compare the absorbance reading by ultraviolet and visible (UV-VIS) spectrophotometer

3. calculate the percentage DPPH Scavenging activity of the crude extract.

4. calculate the percentage DPPH Scavenging activity of the fraction from column chromatography

5. identify the functional groups of the most bioactive fraction through FT-IR and GC-MS.

\section{RELATED STUDIES}

Avicennia alba Blume. (Mangrove, Family Avicenniaceae)

Avicennia alba comes from the words 'Alba' and 'putih' which mean 'white' in Latin and Malay, respectively. It is usually found on newly formed mudbanks on the seaward side or along and near rivers. It is considered a pioneering species of sheltered shores. This shrub or tree is up to 1020 meters tall with barks which are somewhat brown, smooth or slightly rough but not fissured. It has pencil-like pneumatophores and may have stilt roots. The leaves are generally long and pointed, shiny dark green above with white underside. The leaves and fruit shapes of Avicennia alba may be 'non-standard' if the tree is growing in the shade or affected by low nutrients or other difficult conditions. Flowers are small, yellow in clusters that are less crowded together. The fruit is generally long, teardrop shaped with long tapering pointed tip (Fig.1) (Tan, 2011).

This fast-growing mangrove tree is among the few used in replanting mangroves to protect coastlines (the others are Sonneratia and Rhizophora). The bark and seeds are used in fish poison while its resin in birth control. (Tropical Plant Book, 2011). The seeds are also a source in making ointment for treating skin diseases and wounds (National Parks Board, 2011). 


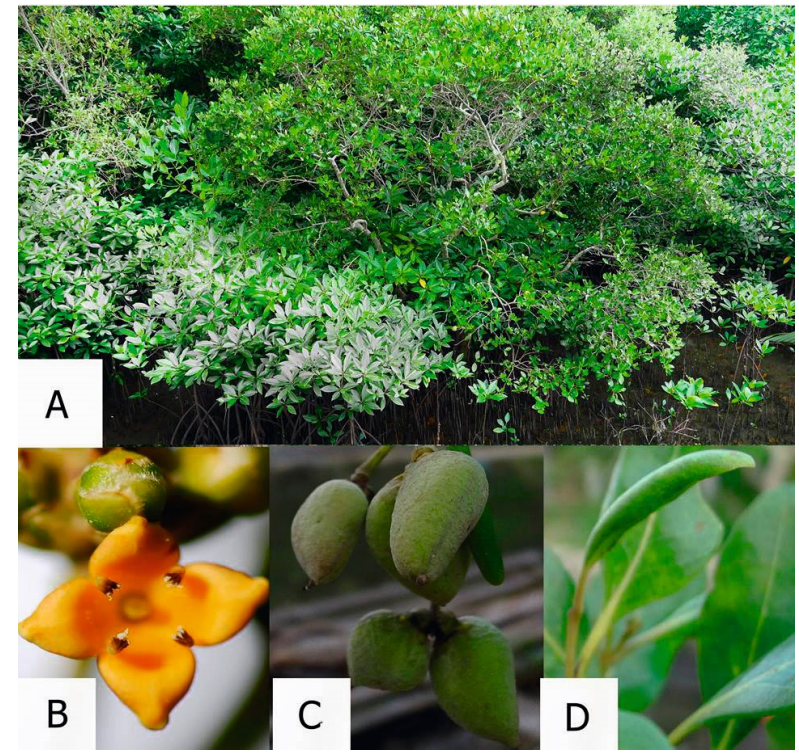

Figure 1. (A.) Habit of Growth of Avicennia alba Blume (Api-api): photo taken at De la Paz, Cortes, Bohol Inset: (B.) flower, (C.) fruit \& (D.) leaves

Only a few studies have been conducted on the species of mangrove, Avicennia alba. These include the antimicrobial activity of its crude extracts (Vadlapudi, \& Naidu, 2009), the protective effect of Avicennia alba leaves on gastric mucosal damage induced by ethanol (Al-Attar, 2011), the isolation and structural elucidation of the new naphthoquinones and their analogues from the stem of the said plant (Ito, Katsuno, Kondo, Tan, \& Furukawa, 2000), and the antidiarrheal and antinociceptive activities of its leaves (Rahman, Biswas, Bala, Shill, \& Bose, 2011). Other researches have been made on other mangrove species especially on the anti-oxidant activity using the extracts of the different parts of the plants, but not on Avicennia alba.

The anti-oxidant activities of bark extract of two Indian mangrove plants, Bruguiera cylindrica and Ceriops decandra were investigated as to its total phenolic content, total flavonoid content, and its antioxidant activities. The results of the study revealed that both mangroves yielded a positive content of phenolic and flavonoid and that the methanol extracts of both mangroves exhibited high antiradical activity against DPPH, ABTS 
and $\mathrm{OH}$ radicals. It was then concluded that both plants can be considered good sources of natural antioxidants for medicinal uses. Further studies, however, are necessary to isolate active principles responsible for the overall antioxidant activity of the extracts (Krishnamoorthy, Sasikumar, Shamna, Pandiarajan, Sofia, \& Nagarajan , 2011).

A similar study for the total phenolic content and antioxidant activity of Bruguiera gymnorrhiza mangrove was investigated by Haq, Sani, Hossain, Taha, \& Monneruzzaman (2011). Their work utilized the methanolic, ethanolic and chloroform crude extracts of leaves and barks of the said mangrove species to find out its phenolic content. For its antioxidant activity, the DPPH - 1,1-diphenyl-2-picrylhydrazyl free radical scavenging assay was employed. The results stated that among all the extracts, ethanol extract of barks of $B$. gymnorrhiza had the highest amount of phenolic compounds while the chloroform extract of leaves showed the lowest amount of phenolic compounds. As to the results of DPPH assay, the best scavenging activity among the extracts was achieved from ethanolic extracts of barks while the lowest activity was on the chloroform extracts of leaves.

The work of Banerjee, Chakrabarti, Hazra, Banerjee, Ray, \& Mukerjee (2008) investigated the total phenolic content and the antioxidant activity of 23 extracts from different plant parts (leaves, stem bark, and root) of 6 mangroves and 4 mangrove associates. Among the name of mangrove plants included were Avicennia alba, Aegiceras corniculatum, Bruguiera gymnorrhiza, Ceriops decandra, Rhizophora mucronata, Sonneratia apetala, Ipomoea pes-caprae, Acanthus illicifolius, Sesuvium portulacastrum, and Suaeda maritima. The total phenolic content was expressed as gallic acid equivalents (GAE) in milligram per gram of dry material. Results revealed that there was a wide variation in the amount of total phenolics in mangrove plant materials ranging from 4.40 to $94.41 \mathrm{mg}$ GAE/g dry material. Among leaves, the highest total phenolics content was found in Sonneratia apetala and lowest in Suaeda maritima. Among stem bark, the highest was found in Ceriops decandra and lowest in Avicennia alba. Among root materials, Ceriops decandra was found to contain highest phenolic component and the lowest was found in Avicennia alba. For the antioxidant power of mangrove plant materials, its reducing power were evaluated as mg Ascorbic Acid Equivalents (AAE) / g dry material. The reducing ability of the plants was high in Ceriops decandra (stem) and the lowest in Aegiceras corniculatum (root). It was then concluded that the best result was obtained with Ceriops decandra stem bark which is high in phenolic content and showed maximum reducing ability. 
A study of Boopathy and Kathiresan (2010) mentioned that the marine floras are rich in medicinally potent chemicals predominantly belonging to polyphenols and sulphated polysaccharides. Polyphenols are widely distributed in plants and they are reportedly acting as free radical scavengers, antimicrobial, and anticancer agents. Mangroves contain high amounts of polyphenols such as phenolic acids, flavonoids, anthocyanidins, lignin, tannin, catechin, epicatechin, epigallocatechin and gallic acid. These phenolic compounds have shown many healthbenefiting bioactivities, such as antioxidant, anticancer, antiviral, antiinflammatory, and ability to inhibit human platelet aggregation. Of the anticancer compounds extracted, it was reported that the marine algae contributed $65.63 \%$, the mangroves $28.12 \%$, and the bacteria $6.25 \%$. The marine organisms especially marine flora has a great promise for providing potent, cheaper, and safer anticancer drugs, which deserve an extensive investigation.

\section{METHODOLOGY}

Collection and Preparation of Plant Material. The fresh leaves of Avicennia alba were collected from De la Paz, Cortes, Bohol where it is abundantly found. The leaves were rinsed several times with running water to remove any foreign matters such as dust and dirt. It was wiped with clean dry cloth and was cut into pieces.

\section{EXTRACTION PROCEDURE}

Maceration method. Two hundred grams of Avicennia alba leaves was placed in each four 500-mL Erlenmeyer flask and was added with enough $95 \%$ ethanol to submerge the leaves. The mixture was allowed to stand for 72 hours with frequent agitation. It was covered with a lid and was filtered using a Buchner funnel. The filtrate was pooled after and was reduced to one-third of its original volume using a 4001 Heidolph rotary evaporator. The crude ethanol extractive was then placed in an Eppendorf vacufuge at $450 \mathrm{C}$ for complete solvent removal and was labeled as the ethanol-free extract. The same procedure of maceration was repeated for another four $500-\mathrm{mL}$ Erlenmeyer flask each filled with another 200 grams of Avicennia alba leaves but the menstruum used was petroleum ether instead of ethanol. The petroleum-free extract was labeled.

Preparation of test solutions. To prepare test solutions from the extracts with a final concentration of $300 \mu \mathrm{g} / \mathrm{mL}, 1200 \mu \mathrm{g}$ of the petroleum ether-free extract was dissolved in sufficient amount of ethanol to make 
$2 \mathrm{~mL}$ solution (TSA) and another $1200 \mu \mathrm{g}$ of the ethanol-free extract was dissolved in sufficient amount of ethanol to make $2 \mathrm{~mL}$ solution (TSB). This was then ready for DPPH free radical assay.

Phytochemical Screening. The crude extract of the plant underwent phytochemical screening to detect the presence of alkaloids, saponins, cardiac glycosides, tannins, flavonoids, terpenoids, steroids, and anthraquinones. Methods of testing for bioactive properties in a plant extract were based on the work of Ara, Saleh-e-In, Ahmed, Ahmed, Hashem, \& Bachar (2010).

DPPH Free Radical Scavenging Assay. The preparation of 1,1diphenyl-2-picrylhydrazyl (DPPH)-ethanol stock solution for the DPPH Free Radical Scavenging Assay was based on the work of Molyneux (2004).

Preparation of positive control. Exactly $1200 \mu \mathrm{g}$, of ascorbic acid powder was dissolved in sufficient amount of $95 \%$ ethanol using a vacufuge tube to make two $\mathrm{mL}$ of a positive control with a concentration of $300 \mu \mathrm{g} / \mathrm{mL}(P)$.

Preparation of negative control. Absolute $95 \%$ ethanol solution was used as a negative control $(\mathrm{N})$. The total amount of $95 \%$ ethanol in one trial was $2 \mathrm{~mL}$.

DPPH radical scavenging assay. The capacity of the cuvette was four $\mathrm{mL}$. For the optimum analytical accuracy, the mixtures were $2 \mathrm{~mL}$ DPPH solution and $2 \mathrm{~mL}$ reductant. Hence, $2 \mathrm{~mL}$ of DPPHethanol stock solution were prepared in four test tubes. Using a micropipette, $2 \mathrm{~mL}$ test solutions, positive control and negative control were added separately to each test tube. Three trials and five replicates were done for each of the test solutions and the controls.

After the addition of different solutions, the reaction was observed if free radicals were scavenged by observing the color change from purple to yellow. Color reaction of each solution was observed and recorded. After tapping the tubes gently to facilitate the reaction, it was wrapped with aluminum foil for incubation. Incubating promotes reaction and mimics the body temperature that is why the tubes were incubated at $37^{\circ} \mathrm{C}$ for an hour and were allowed to stand for 30 minutes at room temperature. Each solution was transferred into the cuvette and the absorbance of the test solutions, positive control and negative control were immediately measured. 
The reduction in the number of free radicals was measured by reading the absorbance at $517 \mathrm{~nm}$ using the UV-VIS Spectrophotometer 1601 (Shimadzu). Absorbance reading was recorded. The measurement of the absorbance was done in three trials, and five replicates of each solution were utilized. A change of color from purple to yellow and a decrease in absorbance relative to the negative control were the two parameters used in the determination of the antioxidant activity of the test solution (Fig. 3). Percent inhibition or percent scavenging is the extent of the ability of the sample to inhibit DPPH free radical oxidation reaction. The \% inhibition of each solution (Banerjee, Chakrabarti, Hazra, Banerjee, Ray, \& Mukerjee, 2008; Wagay and Deepak, 2011) was calculated as follows:

$\%$ DPPH free radical $=$ absorbance of negative control - absorbance of test solution $\times 100$

Scavenging activity

absorbance of negative control

Percent DPPH free radical scavenging activity is the extent of the ability of the sample to inhibit oxidation relative to the ascorbic acid as the positive control.

\section{COLUMN CHROMATOGRAPHY}

Preparation of Column by Wet Packing. Before a glass column was filled with silica gel, as the stationary phase, it was cleaned first and dried. Cotton was placed at the bottom of the tube enough to prevent passage of the solid stationary phase and not too thick to avoid huge amount of trapped air. The slurry poured inside the glass column was prepared by mixing the 25 grams of silica gel with $70 \mathrm{ml}$ solvent (Chloroform : methanol $7: 3)$ of the mobile phase. The silica gel slurry was then slowly poured inside the glass column. For maximum efficiency, the column was evenly and uniformly packed to avoid air bubbles during packing. The adsorbent was allowed to stand for four to five hours to settle it gradually. The column tip was opened to remove some solvent while packing. A layer of sand was added to the top of the adsorbent to avoid disturbance of the surface while the solvent was added. Thickness of the sand beds was 0.5 $\mathrm{cm}$.

Sample Application. The crude ethanol extract $(1 \mathrm{~g})$ was dissolved first in $20 \mathrm{ml}$ of solvent $\left(\mathrm{CHCl}_{3}\right.$ : methanol 70:30). The resulting solution in about $1-1.5 \mathrm{ml}$ was applied evenly to the top of the column using a glass dropper. It was applied by passing it to the rim of the column and was allowed to drain onto the column. Any disturbance of the column could have led to an uneven separation. 
Elution of Sample. In order for the crude ethanol extract sample to be eluted, the mobile phase solvent chloform and methanol (70:30) or the eluting solvent was added into the column. A little amount of solvent was added around the inner perimeter of the column then the mobile phase left was gently added directly into the middle of the column. Every $10 \mathrm{ml}$ of the sample was collected in a suitable container. To avoid channels and cracks in the column, the eluting solvent must be continually added.

TLC (Thin Layer Chromatography). Fractions 1, 2, 3, 4, 5, 6, 7, 8,9 , and 10 collected from column chromatography were subjected to Thin Layer Chromatography. Fractions with the same TLC profile based on similar Rf values were pooled ready for testing its antioxidant activity.

Fourier Transform-Infrared Spectrometer \& Gas Chromatography Mass Spectrometer. The most active of the pooled fractions (fractions 1 and 2) after DPPH assay underwent FT-IR analysis and GC-MS. A sample was submitted to De La Salle University for the determination of functional group present in it.

Statistical Treatment. The difference of means of the four test solutions of petroleum-free extract (TSA), ethanol-free extract (TSB), Ascorbic acid solution (P) and 95\% ethanol $(N)$ and of the two sets of fractions (fractions 1 and 2 and fractions 4 and 5 ) in the results of DPPH free radical assay were analyzed using one-way ANOVA and significant level was set at $p$-value $<0.01$. The significant difference among the test solutions were compared through post hoc analysis. StatPlus 2009 Software program was used for statistical analysis.

\section{RESULTS AND DISCUSSION}

Physical Description of the Crude Extracts and Solvent-Free Extracts. After macerating Avicennia alba leaves for 48 hours, the crude ethanol extractive obtained was dark green in color while the crude petroleum ether extractive was light yellow-green. Further evaporation yielded a dark green-black ethanol-free extract and light yellowgreen petroleum ether free extract (Table 1). 
Crude Extracts in DPPH Free Radical Scavenging Assay. The petroleum ether-free extract (TSA), ethanol-free extract (TSB) and positive control (ascorbic acid solution) at final concentration of $300 \mu \mathrm{g} /$ $\mathrm{mL}$ was subjected to DPPH free radical scavenging assay.

Table 1. Determination of Color Change of 1,1-Diphenyl-1-Picrylhydrazyl (DPPH)

\begin{tabular}{|c|c|c|}
\hline Test Solution & Results & Interpretation \\
\hline Petroleum-Free Extract (TSA) & Purple & Negative \\
\hline Ethanol-Free Extract (TSB) & Yellow & Positive \\
\hline $\begin{array}{l}\text { Positive Control (Ascorbic Acid } \\
\text { solution) }\end{array}$ & Yellow & Positive \\
\hline Negative Control (95\% Ethanol) & Purple & Negative \\
\hline
\end{tabular}

The absorbance of the test solutions were determined using UVVIS Spectrophotometer 1601 (Shimadzu) at $517 \mathrm{~nm}$ wavelength. The absorbance of the negative control showed the highest absorbance reading with mean value of $0.3811 \pm 0.086$ followed by petroleum etherfree extract at $0.3251 \pm 0.113$. The positive control showed the lowest absorbance reading at $0.0867 \pm 0.026$ followed by ethanol-free extract at $0.1156 \pm 0.031$ (Table 3).

The petroleum ether-free extract (TSA) had mean percentage scavenging activity values of $15.99 \% \pm 11.04$ while ethanol-free extract (TSB) had mean values of $68.24 \% \pm 12.23$. Positive control $(P)$ had the highest result at $76.43 \% \pm 9.22$ (Fig. 2). 


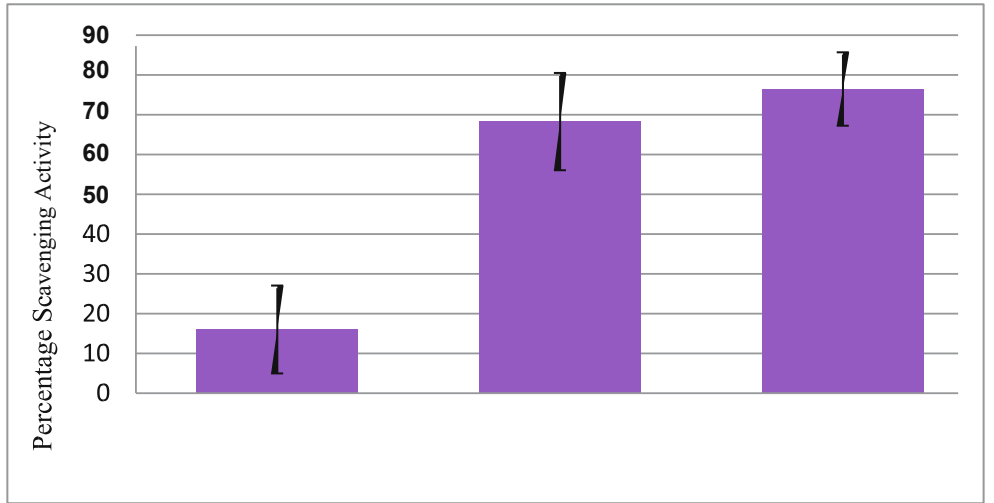

Figure 2. Mean Percentage Scavenging Activity of Crude Extracts

The results of the DPPH free radical scavenging assay were subjected to statistical analysis using one-way ANOVA (Table 2). There was significant difference among the test solutions with respect to their antioxidant activity. A post hoc analysis compared the test solutions revealing four groups having significant differences among their means.

Table 2. One Way ANOVA of the Percent Scavenging Activity of Crude Extracts

\begin{tabular}{lrrrrrr}
\hline \multicolumn{1}{c}{ Source } & d.f. & SS & MS & F & p-level & F crit \\
\hline $\begin{array}{l}\text { Between Gr } \\
\text { oups }\end{array}$ & 3 & 12895.4830 & 4298.4943 & 48.1382 & $1.83 \times 10^{-05}$ & 7.5910 \\
$\begin{array}{l}\text { Within Gro } \\
\text { ups }\end{array}$ & 8 & 714.3585 & 89.2948 & & $(p<0.01)$ & \\
Total & 11 & 13609.8415 & & & & \\
\hline
\end{tabular}

Table 3. Post Hoc Analysis

Tukey HSD Test for Differences Between Means

$p$ values

\begin{tabular}{lrc}
\hline N vs $P$ & $9.38 \times 10^{-05}$ & Significant \\
$N$ vs TSA & 0.2444 & Insignificant \\
$N$ vs TSB & 0.0001 & Significant
\end{tabular}




$\begin{array}{llr}P \text { vs TSA } & 0.0003 & \text { Significant } \\ P \text { vs TSB } & 0.7157 & \text { Insignificant } \\ \text { TSA vs TSB } & 0.0006 & \text { Significant }\end{array}$

Phytochemical Screening by Test Tube Method. The phytochemical screening of ethanol-free extract which had the positive DPPH free radical scavenging activity revealed the presence of bioactive constituents that may be responsible for such significant antioxidant results (Table 4).

\section{Table 4. Constituents Detected through Phytochemical Screening}

\begin{tabular}{|c|c|c|c|c|}
\hline Tests & $\begin{array}{c}\text { Constituent } \\
\text { Tested }\end{array}$ & $\begin{array}{l}\text { Expected } \\
\text { Result }\end{array}$ & Actual Result & Inference \\
\hline $\begin{array}{l}\text { Mayer's } \\
\text { reagent }\end{array}$ & Alkaloids & $\begin{array}{l}\text { Creamy white } \\
\text { precipitate }\end{array}$ & $\begin{array}{l}\text { Light yellow } \\
\text { solution; no ppt. }\end{array}$ & $\begin{array}{l}\text { Negative } \\
\text { result }\end{array}$ \\
\hline $\begin{array}{l}\text { Dragendorff's } \\
\text { reagent }\end{array}$ & Alkaloids & $\begin{array}{l}\text { Red-orange } \\
\text { precipitate }\end{array}$ & $\begin{array}{l}\text { Yellow solution; } \\
\text { no ppt. }\end{array}$ & $\begin{array}{l}\text { Negative } \\
\text { result }\end{array}$ \\
\hline Frothing & Saponins & $\begin{array}{l}\text { Presence of } \\
\text { froth }\end{array}$ & $\begin{array}{l}\text { Froth was } \\
\text { observed }\end{array}$ & Positive result \\
\hline Emulsification & Saponins & $\begin{array}{l}\text { Emulsification } \\
\text { observed }\end{array}$ & Emulsified layer & Positive result \\
\hline $\begin{array}{l}\text { Keller-Killiani } \\
\text { test }\end{array}$ & $\begin{array}{l}\text { Cardiac } \\
\text { glycosides }\end{array}$ & $\begin{array}{c}\text { Reddish } \\
\text { brown ring at } \\
\text { interface; upper } \\
\text { layer will turn } \\
\text { bluish-green } \\
\text { upon standing }\end{array}$ & $\begin{array}{c}\text { Yellowish } \\
\text { brown ring at } \\
\text { interface; bluish } \\
\text { green (upper } \\
\text { layer) }\end{array}$ & Positive result \\
\hline $\begin{array}{c}\text { Ferric chloride } \\
\text { test }\end{array}$ & Tannins & $\begin{array}{l}\text { Brownish green } \\
\text { or blue-black } \\
\text { coloration }\end{array}$ & $\begin{array}{l}\text { Brownish green } \\
\text { coloration }\end{array}$ & Positive result \\
\hline $\begin{array}{c}\text { Lead acetate } \\
\text { test }\end{array}$ & Tannins & $\begin{array}{l}\text { Yellow or red } \\
\text { precipitate }\end{array}$ & Yellow ppt. & Positive result \\
\hline Tests & $\begin{array}{l}\text { Constituent } \\
\text { Tested }\end{array}$ & $\begin{array}{l}\text { Expected } \\
\text { Result }\end{array}$ & Actual Result & Inference \\
\hline $\begin{array}{l}\text { Flavonoids } \\
\text { Method } 1\end{array}$ & Flavonoids & $\begin{array}{l}\quad \text { Yellow } \\
\text { coloration that } \\
\text { disappears on } \\
\text { standing }\end{array}$ & $\begin{array}{c}\text { Yellow turbidity } \\
\text { vanished }\end{array}$ & Positive result \\
\hline $\begin{array}{l}\text { Flavonoids } \\
\text { Method } 2\end{array}$ & Flavonoids & $\begin{array}{l}\text { Yellow } \\
\text { coloration }\end{array}$ & $\begin{array}{l}\text { Yellow } \\
\text { coloration }\end{array}$ & Positive result \\
\hline
\end{tabular}




\begin{tabular}{|c|c|c|c|c|}
\hline Salkowski's test & Terpenoids & $\begin{array}{l}\text { Reddish brown } \\
\text { coloration at the } \\
\text { interface }\end{array}$ & $\begin{array}{l}\text { Dark green } \\
\text { color (upper } \\
\text { portion) }\end{array}$ & $\begin{array}{l}\text { Negative } \\
\text { result }\end{array}$ \\
\hline $\begin{array}{l}\text { Liebermann- } \\
\text { Burchard test }\end{array}$ & Steroids & $\begin{array}{l}\text { Greenish color } \\
\text { is produced } \\
\text { which turns } \\
\text { blue on } \\
\text { standing }\end{array}$ & $\begin{array}{c}\text { Dark green } \\
\text { color }\end{array}$ & $\begin{array}{l}\text { Negative } \\
\text { result }\end{array}$ \\
\hline $\begin{array}{c}\text { Anthraquinone } \\
\text { Test }\end{array}$ & Anthraquinones & $\begin{array}{l}\text { Rose-pink color } \\
\text { in the aqueous } \\
\text { layer }\end{array}$ & $\begin{array}{l}\text { Colorless upper } \\
\text { portion; white } \\
\text { purple lower } \\
\text { portion }\end{array}$ & $\begin{array}{l}\text { Negative } \\
\text { result }\end{array}$ \\
\hline
\end{tabular}

Physical Description of the Fractions from Column Chromatography. Fractions 3, 6, 7, 8, 9 and 10 were not included since these did not show any significant spot upon visualization under the UV light both in $365 \mathrm{~nm}$ (long wave) and in $254 \mathrm{~nm}$ (short wave). Basing from the Rf values obtained from the fractions' TLC profiles, the following fractions which showed significant spots under UV light in $365 \mathrm{~nm}$ (long wave), were combined together: fractions $1 \& 2$ and fractions $4 \& 5$. Two sets of fractions were subjected to DPPH free radical scavenging assay.

Fractions in DPPH Free Radical Scavenging Assay. Of the two fractions $(300 \mu \mathrm{g} / \mathrm{mL})$, both the fractions $1 \& 2$ and $4 \& 5$ showed similar color change as the positive control (ascorbic acid) from purple to yellow.

The spectrophotometer readings (517 $\mathrm{nm}$ wavelength) revealed the highest mean value absorbance for negative control at $0.5872 \pm$ 0.292 . Positive control had the lowest absorbance reading $0.0647 \pm$ 0.014 . Fractions 1\&2's absorbance reading at $0.1738 \pm 0.082$ and fractions 4\&5's absorbance reading at $0.2393 \pm 0.056$ concluded that both had DPPH scavenging activity similar with the positive control.

Although the positive control had the highest scavenging activity at $87.88 \% \pm 3.357$ but then fractions $1 \& 2$ and fractions $4 \& 5$ with respective mean values of $69.97 \% \pm 2.439$ and $55.46 \% \pm 11.408$ had no significant difference with it (Fig. 3). 


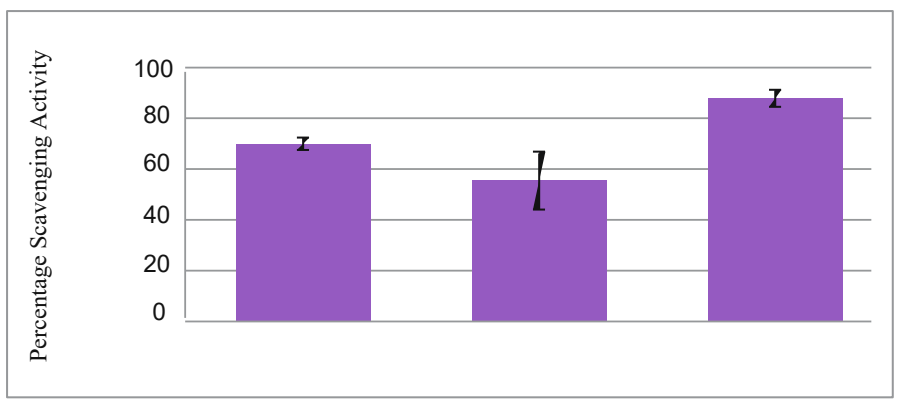

Figure 3. Mean Percentage Scavenging Activity of Fractions

The results of the DPPH free radical scavenging assay were subjected to statistical analysis using one-way ANOVA (Table 5). The $p$-value (6.03 $x 10^{-07}$ ) was obtained suggesting that there was significant difference between the test solutions with respect to their antioxidant activity. A post hoc analysis revealed four groups having significant differences among their means (Table 6).

Table 5. One Way ANOVA of the Percent Scavenging Activity of the Fractions

\begin{tabular}{lcccccc}
\hline \multicolumn{1}{c}{ Source } & d.f. & SS & MS & F & p-level & F crit \\
\hline Between Groups & 3 & 12925.76 & 4308.588 & 116.9291 & $6.03 \times 10^{-07}$ & 7.590992 \\
Within Groups & 8 & 294.7831 & 36.84788 & & $(p<0.01)$ & \\
Total & 11 & 13220.55 & & & & \\
& & & & & & \\
& & & & & &
\end{tabular}

Table 6. Post Hoc Analysis

Tukey HSD Test for Differences Between Means

\begin{tabular}{ccc} 
Fractions 1 and 2 vs Fractions 4 and 5 & 0.0739 & Insignificant \\
Fractions 1 and 2 vs N & $7.37 \times 10^{-05}$ & Significant \\
Fractions 1 and 2 vs $\mathrm{P}$ & 0.0282 & Insignificant \\
Fractions 4 and 5 vs N & $7.85 \times 10^{-05}$ & Significant \\
Fractions 4 and 5 vs P & 0.0008 & Significant \\
$\mathrm{N}$ vs P & $7.36 \times 10^{-05}$ & Significant \\
\hline
\end{tabular}


Fourier Transform-Infrared Spectroscopy Analysis. Table 7 shows the absorption frequencies of the functional groups of the bioactive fraction (fractions 1 and 2) detected through FT-IR.

Table 7. Infrared Absorption Frequencies of Detected Functional Groups

\begin{tabular}{ccc}
\hline Frequencies $\left(\mathrm{cm}^{-1}\right)$ & Bond & Possible Compounds \\
\hline 3439.97 & O-H & Alcohols, Phenols \\
2923.57 & C-H & Alkanes \\
2851.98 & C-H & \\
1644.55 & $-\mathrm{C}=\mathrm{C}-$ & Alkenes \\
1454.85 & $\mathrm{C}-\mathrm{H}$ & Alkanes \\
1401.73 & $\mathrm{C}-\mathrm{H}$ & \\
1152.72 & & Alcohols, Carboxylic Acids, Esters, Ethers \\
971.80 & $\mathrm{C}-\mathrm{O}$ & Alkenes \\
886.76 & $=\mathrm{C}-\mathrm{H}$ & Alkyl Halides \\
662.52 & $\mathrm{C}-\mathrm{Cl}$ & Alkenes \\
\hline & $=\mathrm{C}-\mathrm{H}$ &
\end{tabular}

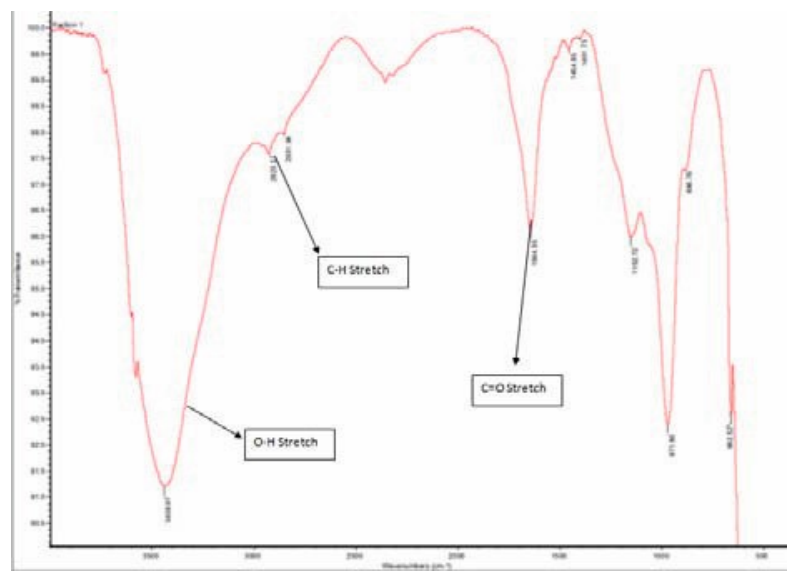

Figure 4. IR Spectrum 
Gas Chromatography-Mass Spectrometry. The ESIMS (positive ion mode) spectrum shows the presence of the molecular ion $[\mathrm{M}+\mathrm{H}]^{+}$at $\mathrm{m} / \mathrm{z}$ $=537.4$. Figure 5 shows the list of compounds when the basic structure of a flavonoid aglycone and the molecular weight range of 536 to 537 were used as search tools.

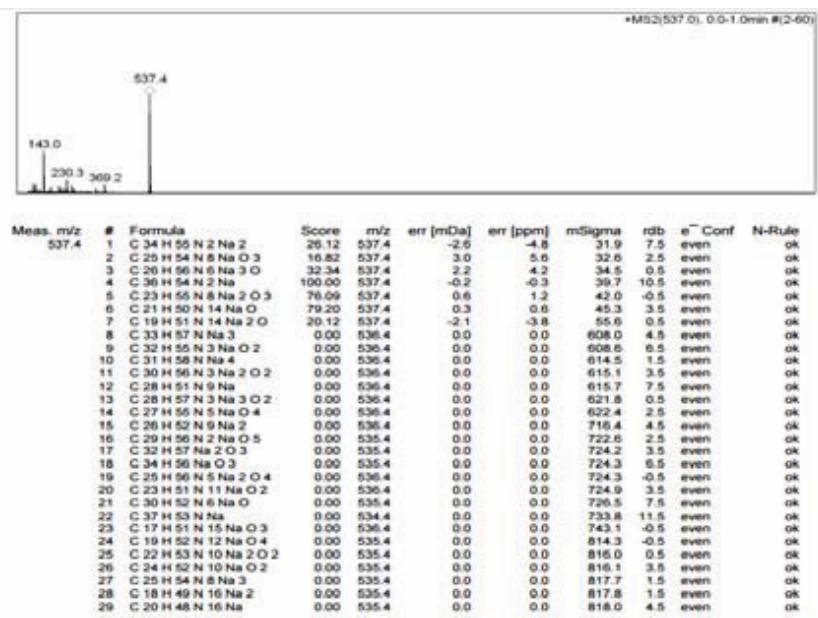

Figure 5. MS Spectrum

\section{DISCUSSION}

Antioxidants of plant origin are believed to help protect the cells from free radical damage. One of the most widely used method for screening the antioxidant activity of plant extract is DPPH radical scavenging assay. Activity of the extract is measured on the basis of the scavenging activity of the stable 1,1-diphenyl-2-Picrylhydrazyl as per study of Molyneux (2004), Shanmugapriya, Ramanathan, \& Renugadevi, (2012), Sahu, Kar, \& Routray (2013), Koleva, Van Beek, Linssen, de Groot, \& Evstatieva (2002). Thus, testing the antioxidant activity of the Avicennia alba leaf extracts was evaluated here using the DPPH scavenging assay through observation of the color change of from purple to yellow and a decrease of absorbance reading as measured using ultraviolet spectrophotometer at $517 \mathrm{~nm}$. Results revealed that only the ethanolfree extract (TSB) and positive control (ascorbic acid solution) exhibited a color change from purple to light yellow while petroleum ether-free extract and negative control (95\% ethanol) remained purple 
in color. Similarly, Haq, Sani, Hossain, Taha, \& Monneruzzaman (2011) investigated the antioxidant activity of Bruguiera gymnorrhiza, one of the species of mangrove using DPPH free radical scavenging assay. The results of the aforementioned study stated that the best scavenging activity was evident from the ethanolic extracts of the mangrove specie. The absorbance reading of the positive control showed the lowest at $0.0867 \pm 0.026$ followed by ethanol-free extract at $0.1156 \pm 0.031$. According to Sanchez, Garcia, \& Cors (2010), the decrease in absorbance is indicative of the inhibition of radical species formation.

The preliminary phytochemical screening of ethanol-free extract by test tube method, which was determined according to the procedure of Ara, Saleh-e-In, Ahmed, Ahmed, Hashem, \& Bachar (2010), revealed the presence of bioactive constituents. Phytochemicals detected were saponins,cardiac glycosides, tannins, and flavonoids. In the study of Nagababu \& Umamaheswara Rao (2012), phytochemical analysis of Avicennia alba leaf extracts and stem extracts showed a variation of phytochemicals present which may be directly dependent on the kind of solvents used. It could also possibly be attributed to the amount of the crude extract which was not sufficient to detect their presence. In this study, plant constituents like alkaloids, terpenoids, steroids and anthraquinones were not detected contrary to the results of the aforesaid literature. These negative results may be attributed to the solvents used in comparison to the aforementioned study which pointed out that acetone and methanol extracts of both leaf and stem of Avicennia alba displayed more phytochemicals tested than the other extracts. A study of Edeoga, Okwu, \& Mbaebie (2005) described the positive result of steroids is a color change from violet to blue or green which is quite different from the expected result of Ara, Saleh-e-In, Ahmed, Ahmed, Hashem, \& Bachar (2010). Considering this report it can be inferred that steroids was also positive in this study.

For Fourier Transform-Infrared Spectroscopy analysis, the infrared spectrum of the active fraction showed the presence of aliphatic $\mathrm{C}-\mathrm{H}$ bonds, $\mathrm{C}=\mathrm{O}$ bond, and hydroxyl or $-\mathrm{OH}$ bonds. The presence of $-\mathrm{OH}$ groups for alcohols/phenols can be confirmed by the presence of strong and broad $\mathrm{O}-\mathrm{H}$ stretch at $3439.97 \mathrm{~cm}^{-1}$. The medium $\mathrm{C}-\mathrm{H}$ stretch for alkanes can be interpreted at $2923.57 \mathrm{~cm}^{-1}$ and $2851.98 \mathrm{~cm}^{-1}$ while the medium $-C=C$ - stretch at $1644.55 \mathrm{~cm}^{-1}$ may signify the presence of alkenes. Same with the above-mentioned stretch for alkanes, the weak $\mathrm{C}$ $-\mathrm{H}$ bends at $1454.85 \mathrm{~cm}^{-1}$ and $1401.73 \mathrm{~cm}^{-1}$ may indicate the presence of 
alkanes. The medium $\mathrm{C}-\mathrm{O}$ The strong $=\mathrm{C}-\mathrm{H}$ bend at $971.80 \mathrm{~cm}^{-1}$ and $662.52 \mathrm{~cm}^{-1}$ may be observed for the presence of alkenes while, lastly, the medium $\mathrm{C}-\mathrm{Cl}$ stretch at 886.76 may mark the presence of alkyl halides. The detected functional groups together with the result of phytochemical screening tests which showed positive results for saponins shows that the compound/s in the active extract have sugar molecules. The positive result in the phytochemical screening for flavonoids also seems to suggest that the active compound/s is a flavonoid glycoside as shown with its IR spectra.

On the other hand, gas chromatography- mass spectrometry data the ESIMS (positive ion mode) spectrum shows the presence of the molecular ion $[\mathrm{M}+\mathrm{H}]^{+}$at $\mathrm{m} / \mathrm{z}=537.4$. Since the mass is not an accurate mass, a molecular formula cannot be derived from this data. Literature search on the metabolites that have been isolated from Avicennia alba showed naphthoquinones such as that study done by Ito, Katsuno, Kondo, Tan, \& Furukawa (2000). This, therefore, can be an interesting study to pursue as this could possibly result to the isolation of the new compound/s that have not been previously reported.

The database Dictionary of Natural Products showed five compounds when the basic structure of a flavonoid aglycone and the molecular weight range of 536 to 537 were used as search tools. Among these compounds with their chemical name and molecular formula are Clitoriacetal;6Deoxy, 11-O- $\beta$-D-glucopyranoside, $\mathrm{C}_{25} \mathrm{H}_{28} \mathrm{O}_{13}$; Clitoriacetal; 11-Deoxy,6-O$\beta$-Dglucopyranoside, $\mathrm{C}_{25} \mathrm{H}_{28} \mathrm{O}_{13} ; 3^{\prime}, 4^{\prime}, 5,5^{\prime}, 6,7$-Hexahydroxyflavanone;

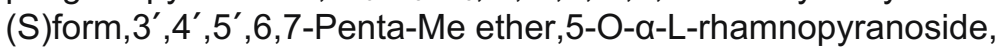
$\mathrm{C}_{26} \mathrm{H}_{32} \mathrm{O}_{12} ; 3,4^{\prime}, 5,7$ - Tetrahydroxy-6-prenylflavanone; (2R,3R)-form,2",3"(2R,3R)-form, 2",3"-Dihydro,3"-hydroxy, 7-O- $\beta$-Dglucopyranoside, $\mathrm{C}_{26} \mathrm{H}_{32} \mathrm{O}_{12}$.

From the phytochemical analysis it can be concluded that phenolic compounds such as saponins, glycosides, tannins, and flavonoids are responsible for such significant antioxidant results. This is confirmed in the works of Gawali \& Jadhav (2011), Banerjee, Chakrabarti, Hazra, Banerjee, Ray, \& Mukerjee (2008), Gao and Xiao (2012). In addition, Sulaiman, Ibrahim, Kasim, \& Ong (2011) mentioned that tannins obtained from the barks of Rhizopora apiculata, a mangrove plant, showed effective antioxidant activity when compared to artificial antioxidants and it therefore act as free radical inhibitor. As mentioned in the study of Pourmorad, Hosseinimehr, \& Shahabimajd, (2006), in many plants phenolic compounds including flavonoids, tannins, and phenolic acid exhibit a strong antioxidant activity. As cited in the study of Cartea, Francisco, Soengas, \& Velasco (2011) and as mentioned by Gao and 
Xiao (2012), phenolic compounds are group of phytochemicals widely found in plants and are characterized by having one aromatic ring with one or more hydroxyl groups attached which directly contribute to the antioxidant properties hence can act as free radical terminators. Furthermore, the functional groups present in the compounds from FT-IR and GC-MS analyses and the secondary metabolites present in phytochemical screening seemed to be responsible for the antioxidant activity of Avicennia alba leaf extracts.

\section{CONCLUSION}

The antioxidant activity of Avicennia alba Blume (1826) leaf extract was observed using 1,1-Diphenyl-2-picrylhydrazyl (DPPH) Free Radical Scavenging Activity Assay. There was a color change from purple to yellow similar to ascorbic acid solution (positive control) and a decrease in absorbance reading relative to $95 \%$ ethanol (negative control). Only the ethanol-free extract exhibited antioxidant activity and in phytochemical screening it showed the presence of saponins, cardiac glycosides, tannins, and flavonoids. Post hoc analysis showed a very comparable result of ethanol-free extract vs ascorbic acid solution with a percentage scavenging activity of $68.24 \% \pm 12.23$ and $76.43 \% \pm 9.22$ respectively. The ethanol-free extract was then subjected to column chromatography for partial purification of its chemical compounds; fractions of the eluates were collected and were pooled according to TLC profile specifically their $\mathrm{Rf}$ values. Fractions $1 \& 2$ and fractions $4 \& 5$ showed similar color change as ascorbic acid solution Fractions 1 and 2 and fractions 4 and 5 with respective mean values of $69.97 \% \pm 2.439$ and $55.46 \% \pm$ 11.408 had comparable results with that of the positive control of $87.88 \% \pm 3.357$ ( $p$-value $<0.01)$. FT-IR analysis showed the presence of aliphatic $\mathrm{C}-\mathrm{H}$ bonds, $\mathrm{C}=\mathrm{O}$ bond, and hydroxyl or $-\mathrm{OH}$ bonds while GC-MS revealed five possible compounds which were based on the molecular ion showed at $\mathrm{m} / \mathrm{z}=537.4$. 


\section{RECOMMENDATIONS}

It is recommended that the maturity of the plant be exclusively considered as specimen for extraction since the maturity of the plant parts affect the quality and quantity of the active constituent, which was not taken into account during the study. In addition to these, the utilization of other plant parts of Avicennia alba Blume and isolation of bioactive principles using different solvents are also recommended. The isolation and characterization of bioactive constituent which could be further used to formulate a drug that has an antioxidant action are recommended. Furthermore, In Vitro and In Vivo studies of Avicennia alba Blume specifically targeting the development of chronic and degenerative conditions i.e. aging, arthritis, autoimmune disorders, cancer, cardiovascular and neurodegenerative diseases are also highly encouraged.

\section{REFERENCES CITED}

Ara, A., Saleh-e-In, M. Md., Ahmed, N. U., Ah med, M., Hashem, A. Md., \& Bachar, S. (2010). Phytochemical Screening, Analgesic, Antimicrobial, and Antioxidant Activities of Bark Extracts of Adenanther apavoninaL. (Fabaceae). Advances in Natural and Applied Sciences, 4(3): 352-360.

Bandaranayke, W.M. (2002). Bioactivities, bioactive compounds and chemical constituents of mangrove plants. Wetlands Ecology and Management, 10(6): 421-452.

Banerjee, D., Chakrabarti, S., Hazra, A.K., Banerjee, S., Ray, J., \& Mukerjee B. (2008). Antioxidant activity and total phenolic of some mangrove in Sundarbans. African Journal Biotechnology, 7(6):805810

Boopathy, N. S., \& Kathiresan, K. (2010). Anticancer Drugs from Marine Flora: An Overview. Journal of Oncology.

Cartea, M.E., Francisco, M., Soengas, P., \& Velasco, P. (2011) Phenolic compounds in Brassica vegetables. Molecules. 16, 251-280.

Choi, H., Lee, J., Park, H., and Sayegh, F. (2009). Antioxidant and 
Antimicrobial Activity of Zostera marina L. Extract. Volume 24(3):179184

Dehpour, AA, Ebrahimzadeh, MA, Nabavi, SF \& Nabavi, SM (2009). Antioxidant activity of methanol extract of Ferula assafoetida and its essential oil composition. Grasas Aceites, 60(4): 405-412.

Department of Health (2013). Leading causes of mortality. Retrieved from https://bit.ly/2kNVqt1, (accessed last 4 January 2016)

Ebrahimzadeh, M.A., Nabavi, S.M., Nabavia, S.F., Bahramian, F.,\& Bekhradnia, AR. (2010).Antioxidant and free radical scavenging activity of $H$. officinalis L. var. Angustifolius, $V$. odorata, $B$. hyrcana and C. speciosum. Pharmaceutical Science, 23(1):29-34.

Edeoga, H., Okwu, D., \& Mbaebie, M. (2005). Phytochemical constituents of some Nigerian medicinal plants. African Journal of Biotechnology. 4 (7), 685-688

Gao M., \& Xiao, H. (2012). Activity-guided isolation of antioxidant compounds from Rhizophora apiculata. Molecules, 17: 10675-10682 Gawali, P. \& Jadhav B.L. (2011). Antioxidant activity and antioxidant phytochemical analysis of mangrove species Sonneratia alba and Bruguier acylindrical. Asian Jr. of Microbiol. Biotech. Env. Sc. Vol. 13, No. (2):2011:257-261

Haq, M., Sani, W., Hossain, A.B.M.S., Taha, R. M., \&Monneruzzaman, K.M. (2011). Total phenolic contents, antioxidant and antimicrobial activities of Bruguiera gymnorrhiza. Journal of Medicinal Plants Research, 5(17): 4112-4118

Ito, C., Katsuno, S., Kondo, Y., Tan, H., \& Furukawa, H. (2000). Chemical constituents of Avicennia alba: isolation and structural elucidation of new napthoquinones and their analogues. Chemical and Pharmaceutical Bulletin, 48(3): 339-343

Kar, D.R., Sudhir Kumar, P., Ghosh, G., \&Sahu, P.K. (2014).Isolation and characterization of flavone from the aerial parts of Avicennia alba Blume. Oriental Journal of Chemistry, 30(2):705-711. 
Koleva II, Van Beek TA, Linssen JPH, de Groot A, Evstatieva LN (2002).

Screening of plant extracts for antioxidant activity: a comparative study on three testing methods. Phytochemical Analysis 13:8-17.

Krishnamoorthy, M., Sasikumar, J.M., Shamna, R., Pandiarajan, C., Sofia, P., \&Nagarajan, B. (2011).Antioxidant activities of bark extract from mangroves, Bruguiera cylindrica (L.) Blume and Ceriops decandra Perr. Indian Journal of Pharmacology, 43(5): 557-561

Kumar, S. (2014). The Importance of Antioxidant and Their Role in Pharmaceutical Science - A Review. Asian Journal of Research in Chemistry and Pharmaceutical Sciences. 1(1), 27- 44

Molyneux, P. (2004). Use of DPPH to estimate antioxidant activity. Songklanakarin Journal Science Technology, 26(2)

Nagababu, P., \& Umamaheswara Rao, V. (2012). Antibacterial and phytochemical screening of leaves and stem extracts of Avicennia alba Blume. International Journal of Applied Biology and Pharmaceutical Technology, 3(4): 399-405

National Parks Board, Singapore. (2011). Avicennia alba. Retrieved from https://bit.ly/2IQ5NwQ, (accessed last 21 November 2011).

Pham-Huy, L.A., Hua, H., \& Pham-Huy, C. (2008). Free Radicals, Antioxidants in Disease and Health. International Journal of Biomedical Science. Vol. 4 No. 2

Pourmorad, F., Hosseinimehr, S.J. and Shahabimajd, N. (2006). Antioxidant activity, phenol and flavonoid contents of some selected Iranian medicinal plants. African Journal of Biotechnology Vol. 5 (11): $1142-1145$

Rahman, M.A., Biswas, S., Bala, V., Shill, A.K., \& Bose, U. (2011). Antidiarrhoeal and antinociceptive activities of leafs Avicennia alba. Pharmacologyonline, 1:492-500

Sahu, R.K., Kar, M., \& Routray, R. (2013). DPPH Free Radical Scavenging Activity of Some Leafy Vegetables used by Tribals of Odisha, India. Journal of Medicinal Plant Studies Vol. 1(4):21-27 
Saikia, L.R., \& Upadhyaya, S. (2011). Antioxidant Activity, Phenol and Flavonoid Content of Some Less Known Medicinal Plants of Assam. International Journal of Pharma and Bio Sciences. 2(2)

Sanchez, J.C., Garcia, R.F., \& Cors, M.M. (2010). 1,1-Diphenyl2picrylhydrazyl radical and superoxide anion scavenging activity of Rhizophora mangle (L.).Pharmacognosy Research, 2(5)

Shanmugapriya, R., Ramanathan, T., \& Renugadevi, G. (2012). Phytochemical Characterization and Antimicrobial Efficiency of Mangrove Plants Avicennia marina and Avicennia officinalis. International Journal of Pharmaceutical \& Biological Archives 2012; $3(2): 348-351$

Sulaiman, S., Ibrahim, D., Kassim, J., \& Hong, L.S. (2011).Antimicrobial and antioxidant activities of condensed tannin from Rhizophora apiculata barks. Journal of Chemical and Pharmaceutical Research. 3(4): 436-444.

Tan, R. (2011). Api-api putih (Avicennia alba) on the Shores of Singapore. Retrieved from https://bit.ly/2keAeMy, (accessed last 18 August 2011).

Terao J and Piskula MK (1997). Flavonoids as inhibitors of lipid peroxidation in membranes. In Rice-Evans CA and Packer L. (editor), Flavonoids in health and disease. Marcel Dekker. New York, pp.277295.

Tropical Plant Book. (2011). Avicennia-alba. Retrieved from http:// tropicalplantbook.com/tropical_coast/mangrove_pages/avicenniaalba .htm, (accessed last 8 August 2011).

Vadlapudi, V., \& Naidu, K.C. (2009). Bioactivity of Marina mangrove plant Avicennia alba on selected plant and oral pathogens. International Journal of Chemtech Research, 1(4): 1213-1216

Wagay, J.A., \& Deepak, V. (2011). Phenolic quantification and anti-oxidant activity of Morchellaesculenta. Pharma and Bio Sciences. 2(1) 
World Health Organization (2012). World Health Statistics. Retrieved from https://bit.ly/2IVTPBA, (accessed last 4 January 2013).

Zhang, Y., Seeram, N.P., Lee, R., Feng, L., \& Heber, D. (2008). Isolation and Identification of StarwberryPhenolics with Antioxidant and Human Cancer Cell Antiproliferative Properties. Journal of Agricultural and Food Chemistry, 56: 670-675 